\title{
Small seawater desalination system based on loop heat pipe principle
}

\author{
Yunhui Peng ${ }^{1}$,Yuanzhou Zheng ${ }^{2, *}$,Tongyao Miao $^{2}$,Peiru Zhou ${ }^{1}$,Yangshi Shao ${ }^{1}$,Li Liang ${ }^{3}$,Lingzhi Feng ${ }^{1}$,Zheng Fang ${ }^{2}$ and \\ Yang Zhang, ${ }^{4}$ \\ ${ }^{1}$ Wuhan University Of Technology, School of Materials Science and Engineering, China \\ ${ }^{2}$ Wuhan University Of Technology, Shipping Institute, China \\ ${ }^{3}$ Wuhan University Of Technology, School of Civil Engineering and Architecture, China \\ ${ }^{4}$ Xi'an Jiaotong University, School of electrical engineering, China
}

\begin{abstract}
The small seawater desalination system based on loop heat pipe principle by using plate capillary pump technology, a new type of radiator spoiler evaporator and soaking plate finned condenser to realize desktop-class solar seawater desalination system. The Venturi tube principle is used to reduce the internal pressure and energy consumption, and solar photoelectric board with electric heating board function is used to solve problems for areas where there is a shortage of electricity and fresh water resources. Full automatic control system is used to realize the full automatic operation of the equipment.Desktop-class light and small seawater desalination equipment enjoys a broad market prospect. It can not only be used in islands, fishing boats, offshore operating platforms and other complex working scenarios, but also can be used as a large ship freshwater resources emergency equipment.
\end{abstract}

\section{System design}

\subsection{Evaporation system}

The evaporation system is composed of a plate capillary pump, an electric heating plate, a heat dissipation chip spoiler evaporator and a solar collector. The capillary pump is designed based on the principle of phase-change heat transfer. As shown in the figure, when the evaporator absorbs heat, the liquid medium inside the capillary core evaporates, and the evaporated gas diffuses to the outside of the capillary core through the fine hole in the capillary core. Through the evaporation loop to the condensation end, the steam dissipates heat and liquefy at the condensation end, and the liquefied medium returns to the inside of the capillary core through the capillary force of the capillary core to complete a cycle to realize the heat transfer.

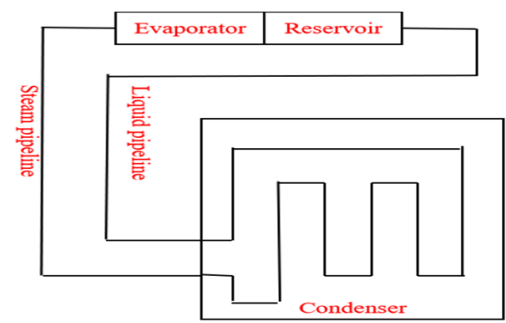

Fig. 1-1 Schematic diagram of heat pipe

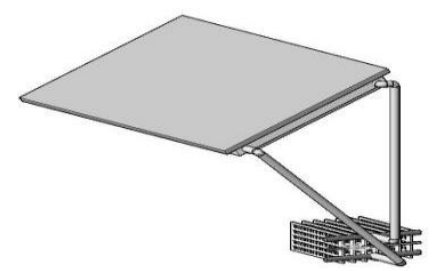

Fig. 1-2 Schematic diagram of evaporation system in capillary pump circuit

*The evaporator shown in the figure is the medium evaporator in the capillary pump, and the radiator in the tank is the heat dissipation section in the circuit.

In the evaporation system, the total size of the evaporator is $100 \mathrm{~cm} \times 430 \mathrm{~cm} \times 65 \mathrm{~cm}, 25$ single heaters are placed parallel to each other with equal spacing between $2 \mathrm{~cm}$ gaps, and the main pipes are connected in parallel. Finally, the evaporator is fixed into a group by the radiator frame, and the structure is shown in Fig. 1-3.

\footnotetext{
* Corresponding author: Yuanzhou Zheng: zhengyunazhou0909@,163.com: Yang Zhang: zy1115169488@stu.xjtu.edu.cn
} 

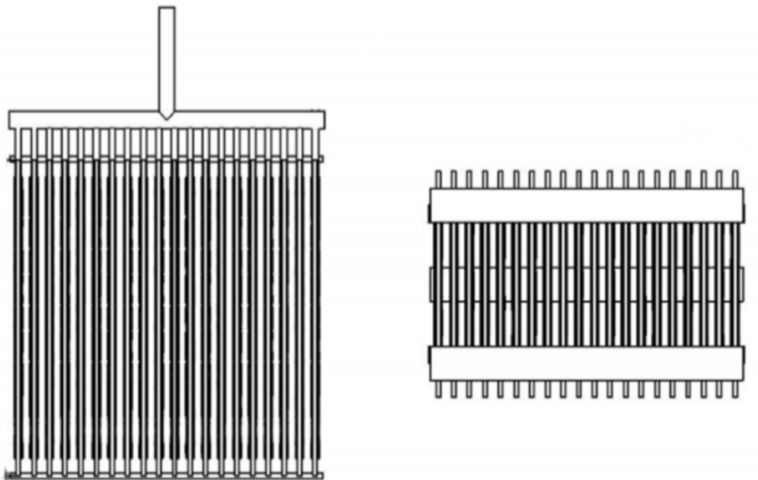

Fig. 1-3 Radiator spoiler evaporator

\subsection{Condensation system}

The main body of the condensation system is composed of cold water inlet and outlet and soaking plate finned condenser, the flow rate of cold water inlet and outlet is controlled by throttle valve, as shown in Fig. 1-4.

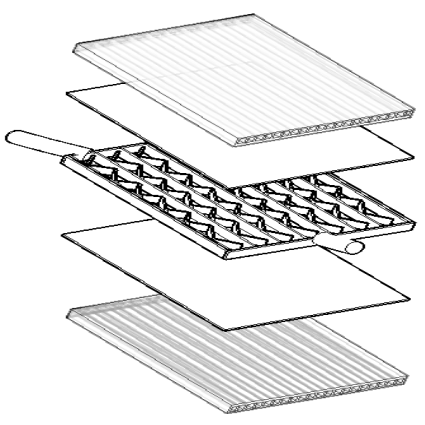

Fig. 1-4 Structure diagram of vapor chamber finned condenser

Soaking plate (vapor chamber) is provided with a cavity. The inner side of the cavity is equipped with a sintered reticular structure. When working, the liquid medium at the bottom of the vacuum cavity absorbs the heat transferred from the steam to the fin at the bottom of the soaking plate, evaporates and diffuses into the vacuum cavity and transmits the heat to the condensation pipe. The condensed liquid is then re-fluxed through a sintering net with capillary force attached to the inner wall of the soaking plate.

The self-made spoiler pipe is composed of an outer wall pipe, five isolation cross plates and six spoiler plates, the structure of which is shown in Fig. 1-5. Five isolation plates are distributed in parallelly and uniformly, and six spoiler plates are interspersed between the isolation plates.

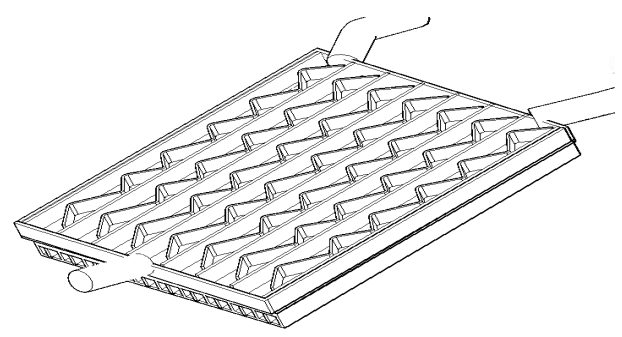

Fig. 1-5 Structure diagram of self-made spoiler pipe
After condensation and liquefaction, the water vapor adheres to the surface of the fin, then drips under the action of gravity and enters the fresh water collection tank. The design of the fin structure greatly increases the contact area between the condenser and water vapor and thus improves the heat transfer speed.

\subsection{Low pressure maintenance system}

The device adopts a sealing structure to maintain the internal pressure of the device, and the Venturi principle is used to maintain the internal low pressure of the device, so that the internal pressure of the device can be reduced to lower the boiling point of seawater evaporation.

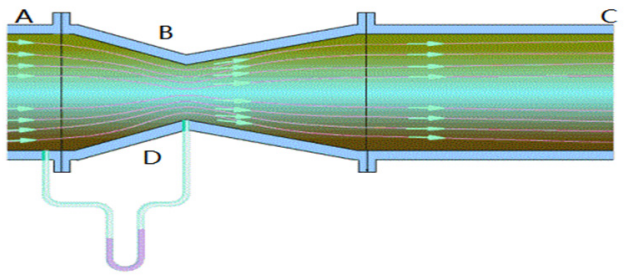

Fig. 1-6 Venturi tube principle

Port $\mathrm{A}$ is the liquid inlet;;Port $\mathrm{C}$ is the liquid outlet, and the cross-section area at $\mathrm{B}$ is reduced, which will increase the flow velocity at $\mathrm{B}$ and decrease the pressure at Port $\mathrm{D}$. The seawater discharged from the condenser is connected to Port A, Port D is connected to the tank, and Port $\mathrm{C}$ is drained to achieve the purpose of vacuuming the fresh water collecting bucket.

\subsection{Fresh water collection and circulating sprinkler system}

The freshwater collection system consists of a freshwater pipeline, an inner and outer annular water pan and a freshwater collection tank, as shown in Fig. 1-7, where fresh water is produced and flows into the freshwater collection tank under the action of gravity. The interior of the tank is connected with the fresh water collection box through the fresh water pipeline to ensure the consistency of the internal pressure between the two, so as to enable the device to operate more stably.

The circulating spray system is composed of a circulating spray pump, an atomizing spray head and a circulating pipeline, which is designed to spray the unevaporated seawater for many times to make full use of the heat When working, the water is sprayed and replenished in the tank by the throttle valve at the inlet and outlet of seawater. When the seawater in the tank reaches a certain height, the circulating spray pump is opened for cyclic spraying. When the evaporated waste salt water reaches a certain concentration, the circulating spray pump stops working.After the waste concentrated salt water is discharged, the valve at the waste water outlet is closed to replenish water and spray again. 


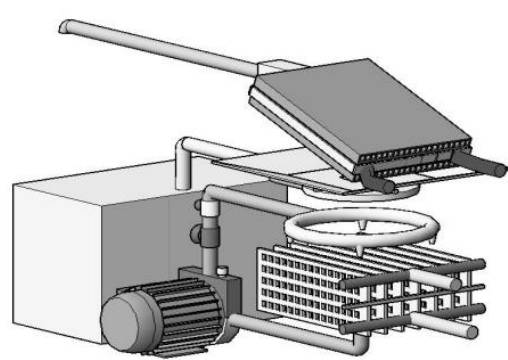

Fig. 1-7 Schematic diagram of fresh water collection system and circulating spray system

\subsection{Power supply system in automatic control system}

In order to realize the convenient functions of one-click start/stop control, fault detection, remote.alarm and mobile terminal control, we design the power supply system and automatic control system. The power supply system and automatic control system are shown in Fig. $1-8$.

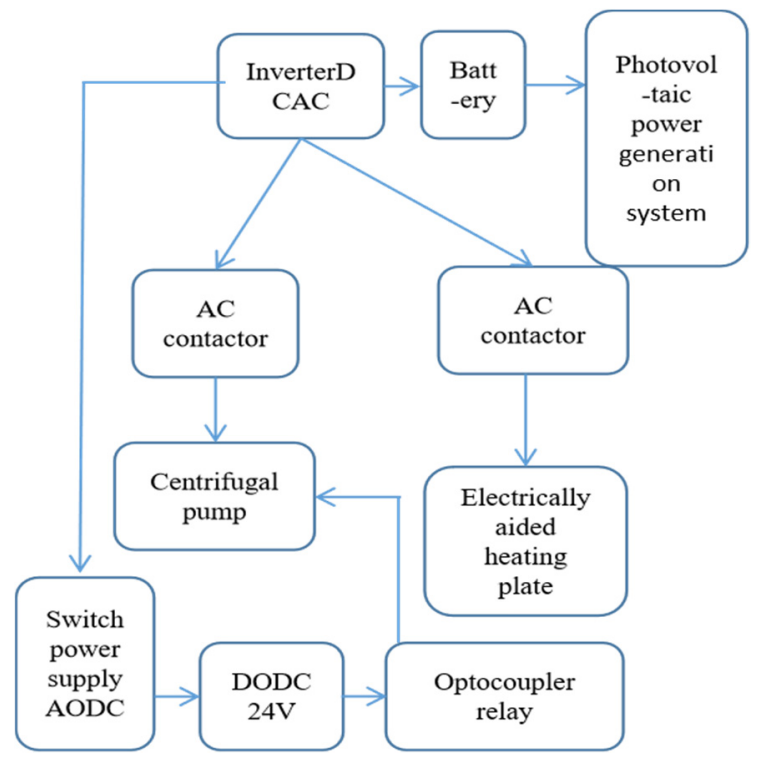

Fig. 1-8 Power supply system and fully automatic control system

\section{Theoretical calculation and yield estimation}

\subsection{Process and Analysis of State Transformation in Thermodynamic Theory}

In this part, a mathematical analysis based on Kinetics model will be established and an analytical solution will be obtained according to the independent functions of each system and the system functions composed into the whole system
Table 3-1.

\begin{tabular}{|c|c|c|}
\hline $\begin{array}{l}\text { Variable } \\
\text { symbol }\end{array}$ & Variable & Meaning \\
\hline$[A]$ & Sea water & $\begin{array}{l}\text { Evaporates involved in the } \\
\text { reaction in a seawater } \\
\text { desalination unit }\end{array}$ \\
\hline$[B]$ & Water vapor & $\begin{array}{l}\text { Water vapor that involves in the } \\
\text { reaction of seawater evaporation } \\
\text { in a seawater desalination unit }\end{array}$ \\
\hline$[C]$ & Fresh water & $\begin{array}{c}\text { Fresh water produced after } \\
\text { condensation }\end{array}$ \\
\hline$\left[B^{\prime}\right]$ & Other gases & $\begin{array}{l}\text { Gases that do not involve in the } \\
\text { reaction in a seawater } \\
\text { desalination unit }\end{array}$ \\
\hline$y_{A}$ & $\begin{array}{l}\text { Water vapor } \\
\text { ratio }\end{array}$ & $\begin{array}{c}\text { Proportion of water vapor in all } \\
\text { gases in seawater desalination } \\
\text { plant }\end{array}$ \\
\hline$y_{B}$ & $\begin{array}{l}\text { Other gases } \\
\text { ratio }\end{array}$ & $\begin{array}{l}\text { Ratio of other gases in seawater } \\
\text { desalination plant in all gases }\end{array}$ \\
\hline$x$ & Solute ratio & $\begin{array}{c}\text { Ratio of other solutes in } \\
\text { evaporation }\end{array}$ \\
\hline
\end{tabular}

In the event of continuous and stable inflow of seawater, the theoretical process based on the kinetics of heat transfer is as follows:

The amount of seawater remains constant at $[\mathrm{A}] 0$, that is, [ A ] N ([ A0 ], ). Under the condition of stability, the analytical solution of the dynamic process of the reaction system is obtained.

With the continuous inflow of seawater, the quantity remains unchanged, and the series system of the first order reaction is constrained by the series system of the first order reaction.

$$
\begin{aligned}
& \frac{\mathrm{d}[\mathrm{A}]}{\mathrm{dt}}=\mathrm{e} \\
& \frac{\mathrm{d}[\mathrm{B}]}{\mathrm{dt}}=\mathrm{k}_{1}[\mathrm{~A}]-\mathrm{k}_{2}[\mathrm{~B}] \\
& \frac{\mathrm{d}[\mathrm{C}]}{\mathrm{dt}}=\mathrm{k}_{2}[\mathrm{~B}]+1(\mathrm{t})
\end{aligned}
$$

The amount of seawater remains constant at $[A]_{0}$, that is, $[A] N\left(\left[A_{0}\right], \quad\right)$, equation (3.1.1),

$$
[\mathrm{B}]=-\frac{\mathrm{k}_{1}[\mathrm{~A}]_{0}}{\mathrm{k}_{2}} \mathrm{e}^{-\mathrm{k}_{2} \mathrm{t}}+\frac{\mathrm{k}_{1}[\mathrm{~A}]_{0}}{\mathrm{k}_{2}}
$$

The final differential equation for desalinated water is

$$
\frac{\mathrm{d}[\mathrm{C}]}{\mathrm{dt}}=-\mathrm{k}_{1}[\mathrm{~A}]_{0} \mathrm{e}^{-\mathrm{k}_{2} \mathrm{t}}+\mathrm{k}_{1}[\mathrm{~A}]_{0}
$$

The time-varying function of desalinated water is obtained as follows

$$
[\mathrm{C}]=\frac{\mathrm{k}_{1}[\mathrm{~A}]_{0}}{\mathrm{k}_{2}} \mathrm{e}^{-\mathrm{k}_{2} \mathrm{t}}+\mathrm{k}_{1}[\mathrm{~A}]_{0} \mathrm{t}-\frac{\mathrm{k}_{1}[\mathrm{~A}]_{0}}{\mathrm{k}_{2}}
$$


According to the properties of the analytical solution function, it can be seen that the total amount of seawater in the device has been stable, the water vapor will be stable to $\mathrm{k} 1[\mathrm{~A}] 0 / \mathrm{k} 2$ with time, and the fresh water will be produced stably at the amount of $\mathrm{k} 1[\mathrm{~A}] 0$.

$$
\mathrm{k}=\frac{\mathrm{y}_{\mathrm{A}} \mathrm{PN}_{\mathrm{A}}}{2 \mathrm{R}} \sqrt{\frac{2 \mathrm{k}_{\mathrm{B}} \mathrm{T}}{\pi \mathrm{m}}} \mathrm{S}^{*}
$$

The rate at which the water molecule leaves the surface should be the same, then the rate at which the water molecule in the saturated vapor collides with the water surface in the equilibrium state can be calculated first. According to the formula of the collision probability between the ideal gas and the wall in statistical physics, there is

$$
\mathrm{k}=\frac{\mathrm{y}_{\mathrm{A}} \mathrm{PN}_{\mathrm{A}}}{2 \mathrm{R}} \sqrt{\frac{2 \mathrm{k}_{\mathrm{B}} \mathrm{T}}{\pi \mathrm{m}}} \mathrm{S}^{*}
$$

Among them: $Z$ is the probability that the water surface per unit area is collided by water vapor molecules; $\mathrm{y}_{\mathrm{A}} \mathrm{P}$ is the partial pressure of water molecules; $\mathrm{k}_{\mathrm{B}}$ is the Boltzmann constant; $\mathrm{S}^{*}$ is the relative heat transfer area, that is, the working area/desalination wall area; $m$ is the mass of a single water molecule; the internal surface area of the tank is $2.633 \mathrm{~m}^{2}$; the overall heat transfer area of the evaporation section is $2.064 \mathrm{~m}^{2}$; the working temperature is $90{ }^{\circ} \mathrm{C}$; The overall heat transfer area of the condensation section is $2.146 \mathrm{~m}^{2}, \mathrm{~S}=0.340$, and the working temperature is $15^{\circ} \mathrm{C}$. The following table shows the meaning and values of the constant in detail:

\begin{tabular}{|c|c|c|}
\hline $\begin{array}{c}\text { Constant } \\
\text { symbol }\end{array}$ & Numerical value & Meaning \\
\hline$m$ & $3 \times 10^{\wedge} 26 \mathrm{~kg}$ & $\begin{array}{l}\text { Mass of a single } \\
\text { water molecule }\end{array}$ \\
\hline$k_{B}$ & $1.38 \times 10^{-23} \mathrm{~J} / \mathrm{K}$ & Boltzmann constant \\
\hline$N_{A}$ & $6.02 \times 10^{\wedge 23}$ & Avogadro constant \\
\hline$R$ & $8.314 \mathrm{~J} \cdot \mathrm{mol}^{-1} \cdot \mathrm{K}^{-1}$ & Ideal gas constant \\
\hline $\mathrm{S}_{1}^{*}$ & 0.327 & $\begin{array}{l}\text { Relative heat transfer } \\
\text { area of evaporation } \\
\text { section }\end{array}$ \\
\hline $\mathbf{S}_{2}{ }_{2}$ & 0.340 & $\begin{array}{l}\text { Relative heat transfer } \\
\text { area of condensation } \\
\text { section }\end{array}$ \\
\hline$T_{1}$ & $90^{\circ} \mathrm{C}$ & $\begin{array}{l}\text { Operating } \\
\text { temperature of } \\
\text { evaporation section }\end{array}$ \\
\hline$T_{2}$ & $15^{\circ} \mathrm{C}$ & $\begin{array}{l}\text { Working temperature } \\
\text { of condensation } \\
\text { section }\end{array}$ \\
\hline
\end{tabular}

Table 3-2 Meaning and value of constant

\subsection{Feedback system}

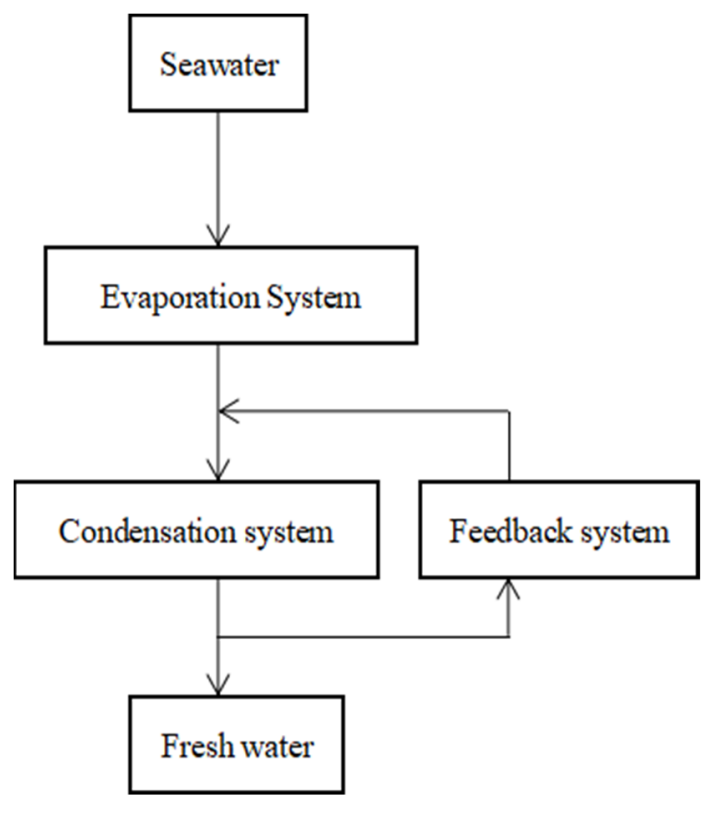

Fig. 3-3 diagram of the system

There is a feedback system in this system, that is, the fresh water output through the Venturi tube is used as monitoring to control the amount of water vapor. The advantage is that the output (that is, the fresh water output) is monitored, so that in the event of impact, that is, when some components (such as pressure) suddenly change, it can still work and gradually return to a stable working state.

In the system, the input is seawater, the intermediate variable is the steam, the output is fresh water. Under the stable working state of the system, the gas-liquid phase transition and the composition of each substance in the seawater desalination system will be analyzed by thermodynamics, which will be used as the working environment of the system.

The whole system is closed and the gases involved in the reaction are only water vapor and other gases that do not involve in the reaction, so the basic condition of Raoult theorem is satisfied. $\mathrm{p}_{\mathrm{A}}{ }^{*}$ : saturated water vapor pressure. $p_{B}$ : the pressure of other gases in the current desalination environment

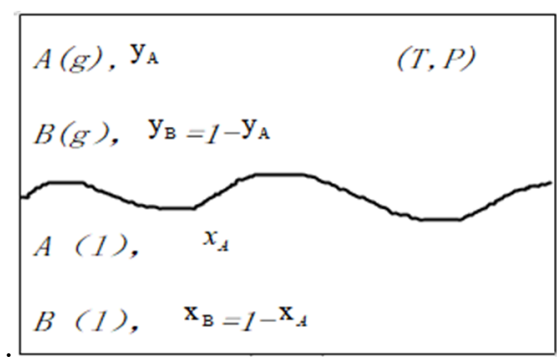

Fig. 3-4 Composition of gases and liquids in seawater desalination unit 


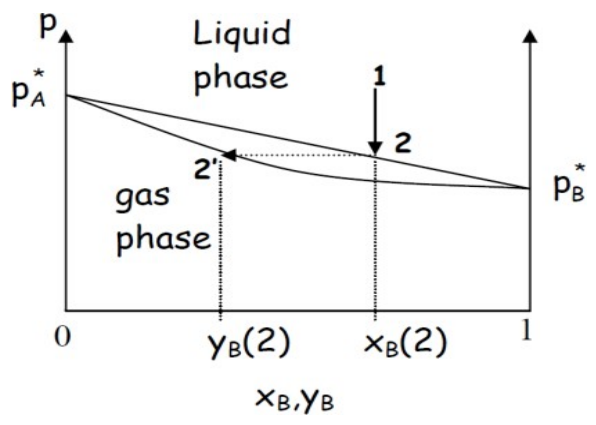

Fig. 3-5 Dynamic changes of gas and liquid in seawater desalination unit

Pressure of other gases in the environment

$$
\left(\mathrm{p}_{\mathrm{A}}^{*}+\mathrm{p}_{\mathrm{B}}^{*}\right) \mathrm{V}=\mathrm{nRT}
$$

According to Raoult's theorem and other air insoluble in water, there is

$$
\mathrm{P}=\mathrm{x}_{\mathrm{A}} \mathrm{p}_{\mathrm{A}}^{*} \quad \mathrm{P}_{\mathrm{B}}=\mathrm{p}_{\mathrm{B}}^{*}
$$

Fig. 5-6 shows the dynamic process, which can be known according to the partial pressure ratio.

$$
\begin{aligned}
& \mathrm{P}=\mathrm{P}_{\mathrm{A}}+\mathrm{P}_{B}=x_{A} p_{A}^{*}+p_{B}^{*} \quad, \mathrm{P}_{\mathrm{A}}=\mathrm{y}_{\mathrm{A}} \mathrm{p} \quad(3.2 .3) \\
& \mathrm{y}_{\mathrm{A}}=\frac{\mathrm{x}_{\mathrm{A}} p_{A}^{*}}{\mathrm{P}_{\mathrm{A}}+\mathrm{P}_{\mathrm{B}}}=\frac{\mathrm{x}_{\mathrm{A}} p_{A}^{*}}{\mathrm{x}_{\mathrm{A}} p_{A}^{*}+\mathrm{p}_{\mathrm{B}}^{*}}=\frac{70 \% \times 70.14}{70 \% \times 70.14+20.1}=0.710
\end{aligned}
$$

Venturi tube reduces the vacuum of the working section to -81.2 , that is, $20.1 \mathrm{kPa}$. The saturated water vapor pressure at $90^{\circ} \mathrm{C}$ is $70.14 \mathrm{kPa}$. After evaporation, the concentration of evaporation solution is $30 \%$, that is, the ratio of solvent (water) is $70 \%$, and the proportion of water vapor in all air is obtained.

$$
\mathrm{y}_{\mathrm{A}}=\frac{\mathrm{x}_{\mathrm{A}} p_{A}^{*}}{\mathrm{P}_{\mathrm{A}}+\mathrm{P}_{\mathrm{B}}}=\frac{\mathrm{x}_{\mathrm{A}} p_{A}^{*}}{\mathrm{x}_{\mathrm{A}} p_{A}^{*}+\mathrm{p}_{\mathrm{B}}^{*}}=\frac{70 \% \times 70.14}{70 \% \times 70.14+20.1}=0.710
$$

The $y_{A}$ obtained is the proportion of water vapor in all gases under stable working condition.

\subsection{Yield of fresh water}

According to Table 3-2, the parameter $\mathrm{k}=\frac{\mathrm{y}_{\mathrm{A}} \mathrm{PN}_{\mathrm{A}}}{2 \mathrm{R}} \sqrt{\frac{2 \mathrm{k}_{\mathrm{B}} \mathrm{T}}{\pi \mathrm{m}}} \mathrm{S}^{*}$ is substituted and

$\mathrm{y}_{A}=0.710$ is obtained from 3.2.4. The reaction rates of the evaporation section and the condensation section are as follows:

$$
\mathrm{k}_{1}=0.274 \quad \mathrm{k}_{2}=0.116
$$

The reaction rate was substituted into the kinetic model, and the theoretical stable fresh water yield was $1.096 \mathrm{~L} / 10 \mathrm{~min}$.

\section{Summary}

According to the function, each part of the device is divided into evaporation, condensation and feedback system. Based on the mathematical analysis of (Kinetics) model of thermodynamic dynamics, the theoretical analysis, calculation and empirical numerical simulation are carried out by using the formula of collision probability between ideal gas and wall in physics and Raoult theorem, and the stable freshwater yield is $1.096 \mathrm{~L} / 10 \mathrm{~min}$.

\section{Acknowledgement}

*National innovation and entrepreneurship training program for college students 20191049712013.

\section{References}

1. Hongwan Fang,Jinfang Chen,Jinming Duan, et al, Research progress on seawater quality and desalination utilization in inshore waters of China. Industrial Water Treatment, 2015-04, 35 (4).

2. Shichaag Wang. Seawater desalination project [M]. Beijing: Chemical Industry Press, 2003.

3. Zhang Xiuzhi, Wang Jing, Hao Jian'an, et al, Utilization model of seawater resources in islands [J]. Water Resources Protection, 2015 (3): 115-118.

4. Meng Yao. Study on the present situation and development countermeasures of seawater desalination in Tianjin [D]. Tianjin University, 2015.

5. Runya Deng.Study on comprehensive utilization and economy of energy in seawater desalination system. Graduate School of Chinese Academy of Sciences, 2009.

6. Yunmo Zhao. Study on seawater desalination by solar low temperature multi-effect distillation [D]. Dalian University of Technology, 2012.

7. Xianhui Pan et al. Development and application of marine seawater desalination plant [B]. State Oceanic Administration, Tianjin Institute of Seawater Desalination and Comprehensive Application, 2015.

8. Ying Yuan. Study on the flow characteristics of gas-liquid two-phase with low liquid content in Venturi tube. Xi'an University of Petroleum, 2018.

9. Yaoming Zhang, Ningyu Zou. Seawater desalination technology and solar energy utilization [J]. Chinese Engineering Science, 2015, (11).

10. Jiyu Qian. Study on flow and heat transfer mechanism of capillary pump circuit. Nanjing University of Science and Technology, 2005. 